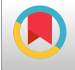

\title{
Prevalence of White Coat Hypertension in Patients with Chronic Kidney Disease
}

\author{
Rozita Mohd, ${ }^{1,}$ Noor Hidayah Yahya, ${ }^{1}$ Rizna Abdul Cader, ${ }^{1}$ Halim A Gafor, ${ }^{1}$ Yazmin Yaacob, ${ }^{1}$ and Rozita \\ $\operatorname{Hod}^{2}$ \\ ${ }^{1}$ Nephrology Unit, Department of Radiology1, Universiti Kebangsaan Malaysia, Kuala Lumpur, Malaysia \\ ${ }^{2}$ Department of Health and Statistics2, Universiti Kebangsaan Malaysia, Kuala Lumpur, Malaysia \\ "Corresponding author: Rozita Mohd, Nephrology Unit, Department of medicine, Universiti Kebangsaan Malaysia Medical Center, Jalan Yaacob Latif, 56000, Kuala Lumpur, \\ Malaysia, E-mail: rozi8286@gmail.com
}

Received 2017 December 21; Accepted 2018 February 03.

\begin{abstract}
Background: Achieving target blood pressure is important in retarding the progression of chronic kidney disease (CKD). Optimizing patient's hypertension solely based on clinic blood pressure could be harmful as it may be masked by white coat hypertension. Objectives: This study aimed at determining the prevalence of white coat hypertension (WCHT) in patients with CKD and correlating this with their target organ damage evidenced by left ventricular hypertrophy (LVH) and carotid intima media thickness (CIMT). Methods: A cross sectional study of 99 patients with CKD (stage 3 to 5 with eGFR Epi of $<60 \mathrm{~mL} / \mathrm{min} / 1.732$ ) at a CKD clinic was conducted. Demographic data, routine blood investigations, and number of antihypertensive medication were recorded. Mean clinic blood pressure of the last 2 visits were taken followed by 24-hour ambulatory blood pressure monitoring (24-hour ABPM), electrocardiography, and carotid ultrasound measurement.

Results: Ninety-nine patients ( 42 males and 57 females) with median age of 62 (55 to 69) years old and predominantly Malays ethnicity were recruited. The prevalence of WCHT was 34.3\% (34 patients), and 65.7\% (65 patients) had sustained hypertension (SHT). Median eGFRs were comparable in both groups $(\mathrm{P}=0.479)$. Despite comparable mean clinic blood pressure $(\mathrm{P}=0.85)$, the WCHT group had significantly lower mean average systolic, daytime, and night time blood pressure when compared with the SHT group $(120.82 \pm 8.24$ vs. $153.20 \pm 18.70),(124.50 \pm 9.51$ vs $155 \pm 18.86),(111.97 \pm 20.07$ vs $146.22 \pm 21.17)$ and diastolic (66.36 \pm 85.79 vs. 82.35 $\pm 12.17)$, (68.71 \pm 10.94 vs 84.11 .8$)$, ( $62.68 \pm 7.78$ vs. $79.28 \pm 12.17)$ respectively $(\mathrm{P}<0.05)$. The trend towards significance of LVH in the WCHT compared with the SHT group $(52 \%$ vs.38\% $(\mathrm{P}=0.066)$ ) and the SHT group had a significantly higher median CIMT $0.80 \mathrm{~mm}$ ( $0.70-0.90)$ as opposed to the $0.60 \mathrm{~mm}$ median of the WCHT group ( 0.60 to 0.70$)(\mathrm{P}<0.05)$. Two-thirds of SHT were non dippers. Conclusions: White coat hypertension is prevalent in CKD. Patients with SHT had significant carotid intima thickening; LVH was detected more commonly in the WCHT group.
\end{abstract}

Keywords: Ambulatory Blood Pressure Monitoring, Carotid Intima, Chronic Kidney Disease, White Coat Hypertension

\section{Background}

Hypertension (HPT) is very common among patients with chronic kidney disease (CKD) with reported prevalence of as high as $80 \%$ to $90 \%$ (1); it can be the cause or the effect of CKD itself. Hypertensive nephrosclerosis was the second leading cause of CKD in Malaysia (24.2\%) (2). Conversely, CKD is the most common cause of secondary HPT (3). In the USA, it has been estimated that hypertension occurs in $23.3 \%$ of non-CKD patients (4). The glomerular filtration rate (GFR) declines more rapidly in hypertensive patients after 40 years of age at the rate of $1.5 \mathrm{~mL} / \mathrm{min}$ per 1.73 $\mathrm{m}^{2}$ per year compared to $0.75-1.00 \mathrm{~mL} / \mathrm{min}$ per $1.73 \mathrm{~m}^{2}$ per year in non-hypertensive counterparts (5).

Achieving blood pressure (BP) control $<130 / 80 \mathrm{mmHg}$ is crucial to reduce Cardiovascular (CV) morbidity and mortality and retard CKD progression (6-8). However, only $27 \%$ of patients with CKD achieved a BP goal of $<140 / 90$ $\mathrm{mmHg}$, and a mere $11 \%$ achieved a BP of $<130 / 85 \mathrm{mmHg}$ (9). This could be because of several factors, such volume overload, over-activation of renin-angiotensin-aldosterone system (RAAS), endothelial dysfunction and arterial stiffness (10). On the other hand, patients may be perceived as hypertensive because of suboptimal BP assessment or underlying 'white coat effect' on BP.

White coat hypertension (WCHT) was defined when the office BP was elevated despite a normal reading while awake or on ambulatory blood pressure monitoring (ABPM). O'Brien et al. redefined WCHT as clinic or office blood pressure of $\geq 140 / 90 \mathrm{mmHg}$ with $\mathrm{ABPM}<130 / 80$

Copyright ( ) 2018, Nephro-Urology Monthly. This is an open-access article distributed under the terms of the Creative Commons Attribution-NonCommercial 4.0 International License (http://creativecommons.org/licenses/by-nc/4.0/) which permits copy and redistribute the material just in noncommercial usages, provided the original work is properly cited. 
mmHg (11). The prevalence of WCHT in normotensive individuals was $13 \%$ and as high as $32 \%$ in hypertensive individuals (12). There was limited data in CKD patients with a reported prevalence of WCHT between $28 \%$ and $31.7 \%$ (1316).

Ambulatory Blood Pressure Monitoring has been recommended by several guidelines in confirming the diagnosis of HPT when the clinic BP is > 140/90 $\mathrm{mmHg}$ (17). Patients with CKD and high clinic BP readings with good control on ABPM displayed better $\mathrm{CV}$ and renal outcomes as compared to patients with SHT (18). Furthermore, ABPM can provide more information on the early morning surge in BP as well as dipping status, both of which are increasingly recognized as cardiovascular risk factors (18).

Hypertension is a well-established predictor for cardiovascular events $(3,19)$. Systolic HPT highly correlates with left ventricular hypertrophy (LVH). In the elderly, systolic $\mathrm{BP}$ increases disproportionately to diastolic $\mathrm{BP}$, resulting in a wide pulse pressure, which is a surrogate marker for arterial stiffness. Hypertension also causes carotid structural changes, such as intima media thickening and plaque (20, 21). Thickening of intima media of the common carotid artery is a useful marker in predicting vascular changes producing atherosclerosis (22).

As there is no local data available on WCHT in patients with CKD, the current study aimed at determining the prevalence of WCHT among patients with CKD and correlating this with target organ damage by measuring LVH and CIMT.

\section{Methods}

This was a cross sectional study on patients with CKD attending the nephrology clinic of UKMMC between November 2014 and January 2016. Inclusion criteria were being an adult patient aged $>18$ and $<80$ years old with CKD stages III to V (CKD EPI GFR $<60 \mathrm{~mL} / \mathrm{min} / 1.73 \mathrm{~m}^{2}$ ) and with clinic BP readings of $\geq 140 / 90 \mathrm{~mm} \mathrm{Hg}$ on 2 clinic visits. This study excluded patients with atrial fibrillation, patients on dialysis or those that had received renal transplantation. Recruitment was done via convenience sampling. After obtaining a written informed consent, a clinical interview, physical examination and demographic data, including age, gender, race, weight, height, comorbidities, and medications were recorded. Laboratory data from the clinic visit and clinic BP readings were recorded. All patients were subjected to 24 hours of ABPM, electrocardiogram (ECG), and ultrasound scan of common carotid artery. Chronic Kidney Disease was defined as either kidney damage or eGFR $<60 \mathrm{~mL} / \mathrm{min} / 1.73 \mathrm{~m}^{2}$ for more than 3 months.
Clinic BP was measured during the nephrology clinic visit ( $8 \mathrm{am}-1 \mathrm{pm}$ ) as per guidelines (23). Next, all patients underwent 24-hour ABPM monitoring using the BPRO machine (model T6400, Healthstats), following a standard procedure (11). The researchers analyzed the mean of 24hour daytime BP, night time systolic and diastolic BP, mean arterial BP, and pulse pressure. More than $80 \%$ technically satisfactory readings during both daytime and night time measurements were accepted as a successful recording or else they were repeated (13). The patients were then categorized to normotensive, WCHT, and Sustained Hypertension (SHT) groups (Table 1). All patients were grouped to dippers or non-dipper based on the night to day systolic blood pressure ratio (13). Patients, who exhibited a reduction of systolic or diastolic BP of $>10 \%$ during the night $(10 \%$ to $20 \%$ ) were categorized as normal dippers, those with $>20 \%$ reduction in night time $\mathrm{BP}$ were excessive dippers, $<10 \%$ in night time BP were non-dippers, and those, who had no drop in night time BP but had a paradoxical rise in BP were reverse dippers. In the current study, the normal dippers and excessive dippers were combined and regrouped as dippers, whereas the non-dippers and reverse dippers were regrouped as non-dippers. Polypharmacy is defined as the requirement of more than 3 agents (24).

Table 1. Classification of Blood Pressure

\begin{tabular}{lcc}
\hline & $\begin{array}{c}\text { Clinic Blood } \\
\text { Pressure, mmHg }\end{array}$ & $\begin{array}{c}\text { Daytime ABPM, } \\
\text { mmHg }\end{array}$ \\
\hline Normotensive [NOR] & $<140 / 90$ & $<130 / 80$ \\
White Coat HPT[WHT] & $\geq 140 / 90$ & $<130 / 80$ \\
Sustained HPT [SHT] & $\geq 140 / 90$ & $\geq 130 / 80$ \\
\hline
\end{tabular}

An ECG was performed and LVH was defined using the Sokolow-Lyon amplitude criteria $(25,26)$.

\subsection{Carotid Intima Media Thickness (CIMT)}

Carotid ultrasound was performed as per the American echocardiographic guidelines (27). Both carotid arteries were scanned to determine the CIMT, using an ultrasound scanner (Siemens SONOLINE G40) with a $7 \mathrm{MHz}$ linear transducer and a transducer aperture of $38 \mathrm{~mm}$. The CIMT images were recorded from a distance between the first echogenic line (lumen-intima interface) and the second echogenic line (media adventitia interface). The CIMT was measured at $1 \mathrm{~cm}$ proximal to the start of the carotid bulb dilatation of the common carotid artery in the far wall, and the maximum CIMT value was recorded. The mean from 3 readings was taken each from both sides and then the maximum CIMT value was recorded for analysis. The ultrasound images were verified by a radiologist, who 
was blinded to the cases. As there was no reference for CIMT values in the local(Asian) population, the matched age and gender CIMT value from the Carotid Atherosclerosis Progression Study (CAPS) was used (20). Carotid Intima Media Thickness values of $\geq 75$ th percentile are considered abnormally high and indicative of increased CVD risk, 25th to 75th percentile are average and are not considered to change CVD risk, whereas values $\leq 25$ th percentile are considered to have lower CVD risk.

The statistical package for social science version 20.0 (SPSS Inc. Chicago, IL) was used for data analysis. After testing for normality, the data were expressed either as mean $\pm \mathrm{SD}$ (standard deviation) or median with IQR (inter quartile range of 25 th percentile; 75 th percentile) based on their normality distribution. Chi-square was used for categorical variables and Student's t-test and Mann Whitney-U test were used for continuous variables. In addition, correlation was determined either by the Pearson coefficient or the Spearman coefficient, based on data distribution. A P value of $<0.05$ was considered significant.

This study received ethics approval from the research ethics committee, Universiti Kebangsaan Malaysia [study code FF-2014-341] and was supported by a grant from the UKMMC Fundamental Research Fund.

\section{Results}

Ninety-nine patients were enrolled with median age of 62 (IQR 55 to 69 ) years old with $42(42.4 \%)$ males and $57(57.6 \%)$ females. The racial distribution consisted of 66 (66.7\%) Malays, 29 (29.3\%) Chinese, and 4 (4\%) Indians. Diabetes was the main aetiology of CKD (46.5\%) followed by glomerulonephritis (23.3\%) and hypertension. The majority of the cases were in stage III and IV CKD; $48.5 \%$ and $40.4 \%$ respectively. The median duration of hypertension was 9 (6 to 17) years with the longest duration being 33 years. Most of the patients had co-morbidities, with dyslipidaemia and diabetes mellitus being the commonest. Based on the world health organization (WHO) classification, the majority of the patients were overweight with a median body mass index (BMI) of $26(26-30) \mathrm{kg} / \mathrm{m}^{2}$. Twenty-six patients were smokers.

The prevalence of WCHT in the current study was 34.3\% $(n=34)$ whereas 65.7\% $(n=65)$ had SHT. Both groups, WCHT and SHT, had comparable laboratory parameters except for a significantly higher serum creatinine in the SHT group as shown in Table 2. Two-thirds of the patients were non dippers (66.7\%).

\subsection{ABPM Measurements}

As expected, the WCHT group had significantly lower $\mathrm{BP}$ on ABPM at all times (Table 3). In addition, there were a few patients in the WCHT group, who had a systolic BP of $<$ $100 \mathrm{~mm} \mathrm{Hg}$. All patients were on anti-HPT treatments with the median number of anti-hypertensive prescribed being 3 agents. Fourty-six (46.5\%) patients required $<2$ antiagents whereas the remaining 53 (53.5\%) patients needed 3 agents. Of these 53 patients, the majority were in the SHT group ( $n=32,60.4 \%)$. There were $44(44.4 \%)$ patients on Angiotensin-Converting-Enzyme (ACE) inhibitor and 22 (22.2\%) were on angiotensin receptor blockade (ARB).

\subsection{Left Ventricular Hypertrophy}

Forty patients (40.4\%) had LVH based on the ECG criteria. There was a higher prevalence of LVH in the WCHT group $(18 / 34,52 \%)$ compared with the SHT group (22/65 and $33.8 \%)$ with a trend towards significance $(\mathrm{P}=0.066)$ (Table 4).

\subsection{Carotid Intima Media Thickness}

The overall median CIMT was 0.70 (0.70 to 0.80$) \mathrm{mm}$. The median CIMT in the WCHT group was 0.60 ( 0.60 to $0.70)$ vs $0.80 \mathrm{~mm}$ (0.70 to 0.90) in the SHT group $(\mathrm{P}<0.01)$. A total of 26 patients were found to have thickened CIMT, of which 25 were in the SHT group (Table 5). Half of the patients with thickened CIMT had concomitant LVH. Age correlated with CIMT in the overall population $\left(\mathrm{r}^{2}=0.198\right.$, $\mathrm{P}=0.049$ ). As the majority of patients, who had thickened CIMT, were in the SHT group, the research further subanalyzed the SHT group to look at significant predictors for the development of CIMT thickening. This study demonstrated that age $\left(r^{2}=0.342, P=0.005\right)$ was the only significant predictor. Based on logistic regression, the independent factors associated with greater risk of obtaining thickened CIMT were pre-existing IHD and age. The probability of having thickened CIMT was $14.3 \%(P=0.001$, CI 95\%) higher with IHD. The probability of having thickened CIMT was increased by $22.6 \%$ ( $\mathrm{P}=0.025$; CI 95\%) by every one year increment of age. On multiple linear stepwise regressions, both variables were still significant $P<0.025,\left(R^{2}=0.051\right.$, adjusted $\left.\mathrm{R}^{2}=0.041\right)$.

\section{Discussion}

Achieving BP target remains a challenge to physicians either due to resistant HPT in CKD or due to the effect of WCHT. Effective treatment ameliorates the harmful effects of uncontrolled HPT and provides renal and CV protection (3-5). However, poor awareness and non-adherence are 2 well-known factors for suboptimal BP control(28). Furthermore, the high prevalence of WCHT among the CKD population leads to misclassification of true BP $(13,14)$. This study found that the prevalence of WCHT in the CKD cohort 
Table 2. Characteristics of Sample in the Two Groups ${ }^{\mathrm{a}}$

\begin{tabular}{|c|c|c|c|}
\hline Characteristics & $\operatorname{WCHT}(n=34)$ & SHT $(n=65)$ & P Value \\
\hline Age, $y$ & $65.50(58-69)$ & $62(52-68)$ & $0.131^{\mathrm{b}}$ \\
\hline Gender & & & $0.143^{c}$ \\
\hline Male & $11(32.4)$ & $31(47.7)$ & \\
\hline Female & $23(67.6)$ & $34(52.3)$ & \\
\hline BMI, $\mathrm{kg} / \mathrm{m}^{2}$ & $27.50(23.75-33)$ & $25(22.50-30.00)$ & $0.087^{\mathrm{b}}$ \\
\hline Smoking status & & & $0.159^{c}$ \\
\hline Smokers & $6(17.6)$ & $20(30.8)$ & \\
\hline Non smokers & $28(82.4)$ & $45(69.2)$ & \\
\hline Diabetes Mellitus & $23(67.6)$ & $39(60)$ & $0.455^{\mathrm{c}}$ \\
\hline Dyslipidemia & $29(85.3)$ & $56(86.2)$ & $0.907^{\mathrm{d}}$ \\
\hline IHD & $3(8.8)$ & $13(20)$ & $0.151^{\mathrm{c}}$ \\
\hline CVA & $4(11.8)$ & $9(13.8)$ & $0.769^{\mathrm{d}}$ \\
\hline CKD Stages & & & $0.157^{\mathrm{d}}$ \\
\hline Stage III & $21(61.8)$ & $27(41.5)$ & \\
\hline Stage IV & $10(29.4)$ & $30(46.2)$ & \\
\hline Stage V & $3(8.8)$ & $8(12.3)$ & \\
\hline \multicolumn{4}{|l|}{ Renal Function Test } \\
\hline Urea, $\mathrm{mmol} / \mathrm{L}$ & $10.41 \pm 4.27$ & $11.17 \pm 4.33$ & $0.404^{\mathrm{e}}$ \\
\hline Creatinine, $\mu \mathrm{mol} / \mathrm{L}$ & $174.00(144.25-195.00)$ & $194.00(137.00-141.00)$ & $0.038^{\mathrm{b}}$ \\
\hline \multicolumn{4}{|l|}{ Fasting Serum Lipid } \\
\hline Triglyceride, mmol/L & $1.68(1.26-2.85)$ & $2.03(1.46-2.77)$ & $0.290^{\mathrm{b}}$ \\
\hline Total Cholesterol, mmol/L & $5.12(4.33-6.13)$ & $5.21(4.40-5.87)$ & $0.897^{\mathrm{b}}$ \\
\hline LDL, mmol/L & $2.62(2.07-3.52)$ & $3.01(2.15-3.51)$ & $0.808^{\mathrm{b}}$ \\
\hline $\mathrm{HDL}, \mathrm{mmol} / \mathrm{L}$ & $1.21(0.98-1.47)$ & $1.14(0.91-1.46)$ & $0.255^{\mathrm{b}}$ \\
\hline CKD-EPI GFR, $\mathrm{mL} / \mathrm{min} / 1.73 \mathrm{~m}^{2}$ & $32.39 \pm 11.15$ & $30.52 \pm 13.03$ & $0.479^{\mathrm{e}}$ \\
\hline
\end{tabular}

Abbreviations: BMI, body mass index; CKP EPI GFR, chronic kidney disease Epidemiology collaboration glomerular filtration rate; CKD, Chronic Kidney Disease; CVA, cerebrovascular accident; HbA1c, Haemoglobin A1c; HDL, high density lipoprotein; IHD, Ischemic heart disease; LDL, low density lipoprotein Urine PCI, urine proteincreatinine index.

${ }^{a}$ Values are expressed s mean $\pm \mathrm{SD} /$ median (IQR) or No. (\%).

${ }^{\mathrm{b}}$ Mann-Whitney U Test.

${ }^{c}$ Pearson Chi Square.

${ }^{\mathrm{d}}$ Likelihood ratio.

${ }^{\mathrm{e}}$ T-test.

was 34.3\%, which is in agreement with the reported literature on both CKD and general populations (9,13-16).

Both the WCHT and SHT group were similar in demographics and in terms of CKD staging despite the SHT group having a higher serum creatinine. However, there was a significant discrepancy between ABPM and clinic BP in both WCHT and SHT groups with a minimum difference of 20 to 30/10 to $20 \mathrm{~mm} \mathrm{Hg}$. This effect was pronounced in the WCHT group proving that clinic BP always overestimates the true BP as demonstrated in other studies (13, 15). The degree of reduction on ABPM at night time went down over the threshold limits of hypoperfusion (SBP of $<$ $100 \mathrm{mmHg}$ ) in the WCHT group. Therefore, intensification of anti-hypertension based on clinic BP would potentially predispose patients to ischemia-induced worsening of renal and CV outcomes (29).

The current study also showed that the patients with CKD were older with co-morbidities, such as ischaemic heart disease (IHD) or stroke. Diabetes mellitus remains the most common cause of CKD, in agreement with the registry of this study $(2,30)$.

The SHT group required more anti HPT medications 
Table 3. Blood Pressure in the Two Groups ${ }^{\mathrm{a}}$

\begin{tabular}{|c|c|c|c|}
\hline Characteristics, mmHg & WCHT $(n=34)$ & $\operatorname{SHT}(n=65)$ & P Value \\
\hline \multicolumn{4}{|l|}{ Clinic } \\
\hline Systolic & $162.09 \pm 20.47$ & $161.34 \pm 14.88$ & $0.85^{\mathrm{b}}$ \\
\hline Diastolic & $80.21 \pm 7.80$ & $81.18 \pm 9.72$ & $0.61^{\mathrm{b}}$ \\
\hline Pulse pressure & $81.88 \pm 19.92$ & $80.15 \pm 16.25$ & 0.64 \\
\hline \multicolumn{4}{|l|}{ ABPM } \\
\hline Systolic & $120.82 \pm 8.24$ & $153.20 \pm 18.70$ & $<0.001^{\mathrm{b}}$ \\
\hline Diastolic & $66.36 \pm 85.79$ & $82.35 \pm 12.17$ & $<0.001^{\mathrm{b}}$ \\
\hline Pulse pressure & $54.47 \pm 9.21$ & $70.84 \pm 19.35$ & $<0.001^{\mathrm{b}}$ \\
\hline \multicolumn{4}{|l|}{ Day time } \\
\hline Systolic & $124.50 \pm 9.516$ & $155.55 \pm 18.86$ & $<0.001^{\mathrm{b}}$ \\
\hline Diastolic & $68.71 \pm 10.94$ & $84.46 \pm 11.88$ & $<0.001^{\mathrm{b}}$ \\
\hline Pulse pressure & $54.79 \pm 10.08$ & $71.09 \pm 18.73$ & $<0.001^{\mathrm{b}}$ \\
\hline \multicolumn{4}{|l|}{ Night time } \\
\hline Systolic & $111.97 \pm 20.07$ & $146.22 \pm 21.17$ & $<0.001^{\mathrm{b}}$ \\
\hline Diastolic & $62.68 \pm 7.78$ & $79.28 \pm 12.17$ & $<0.001^{\mathrm{b}}$ \\
\hline Pulse pressure & $49.29 \pm 18.11$ & $66.94 \pm 18.96$ & $<0.001^{\mathrm{b}}$ \\
\hline \multicolumn{4}{|l|}{ Dipping, \% } \\
\hline Dippers & $7.43 \pm 6.99$ & $5.84 \pm 6.68$ & $0.272^{\mathrm{b}}$ \\
\hline Non Dippers & $9(26.5)$ & $15(23.1)$ & \\
\hline \multirow[t]{2}{*}{ Extreme Dippers } & $21(61.8)$ & $45(69.2)$ & $0.710^{c}$ \\
\hline & $4(11.8)$ & $5(7.7)$ & \\
\hline
\end{tabular}

Abbreviations: SHT, sustained hypertension; WCHT, white coat hypertension.

${ }^{\mathrm{a}}$ Values are expressed s mean \pm SD or No. (\%).

${ }^{\mathrm{b}}$ T-test.

${ }^{\mathrm{c}}$ Likelihood ratio.

perhaps due to their advancement of CKD (31). This study also found that two-thirds of the SHT group were non dippers with a more severe degree of CKD and in keeping with others (8). Multiple factors may contribute to the resistant HPT and loss of dipping in CKD. The renin angiotensine aldosterone system (RAAS) activation, sodium hypersensitivity and baroreflex impairment lead to sympathetic activation and autonomic neuropathy resulting in an increase in extracellular volume, which causes disruption of normal circadian pattern of BP and resistant HPT (32). Furthermore, the endothelial dysfunction could also contribute to the loss of nocturnal dip in BP (10). Hence, the majority of the patients of this study were either on ACE-inhibitor and/or ARB groups as their anti-hypertensive agents.

The prevalence of LVH among patients with CKD has been reported as approximately $40 \%$, which is similar to the current study (33). Interestingly, more patients with LVH were found in the WCHT group as opposed to the SHT
Table 4. Clinical Characteristics of Patients with Left Ventricular Hypertrophy ${ }^{a}$

\begin{tabular}{|c|c|c|c|}
\hline & WCHT $(n=18)$ & $\operatorname{SHT}(n=22)$ & P Value \\
\hline Age, $y$ & $63.83 \pm 9.14$ & $63.82 \pm 11.48$ & $0.996^{\mathrm{b}}$ \\
\hline Gender & & & $0.019^{c}$ \\
\hline Male & $4(22.2)$ & $13(59)$ & \\
\hline Female & $14(77.8)$ & $9(41)$ & \\
\hline BMI, $\mathrm{kg} / \mathrm{m}^{2}$ & $28.98 \pm 4.66$ & $25.18 \pm 3.96$ & $0.008^{\mathrm{b}}$ \\
\hline Smoker & & & $0.265^{\mathrm{d}}$ \\
\hline Yes & $3(16.7)$ & $7(31.8)$ & \\
\hline No & $15(83.3)$ & $15(68.2)$ & \\
\hline Duration of HPT, $y$ & $15(6.00-21.25)$ & $12(9.00-20.00)$ & $0.697^{\mathrm{c}}$ \\
\hline Diabetes Mellitus & $14(77.7)$ & $15(68.1)$ & $0.496^{\mathrm{d}}$ \\
\hline Dyslipidemia & $16(18.8)$ & $20(90.9))$ & $0.833^{\mathrm{d}}$ \\
\hline IHD & $2(11.1)$ & $9(40.9)$ & $0.030^{\mathrm{d}}$ \\
\hline CVA & $2(11.1)$ & $6(27.3)$ & 0.192 \\
\hline $\begin{array}{l}\text { CKD-EPI GFR, } \mathrm{mL} / \mathrm{min} / 1.73 \\
\mathrm{~m}^{2}\end{array}$ & $38.54 \pm 12.72$ & $29.56 \pm 5.64$ & $0.039^{c}$ \\
\hline
\end{tabular}

Abbreviations: BMI, body mass index; CVA, cerebrovascular accident; CKP EPI GFR, chronic kidney disease epidemiology collaboration glomerular filtration rate; IHD, ischemic heart disease.

${ }^{a}$ Values are expressed $s$ mean $\pm \mathrm{SD} /$ median (IQR) or No. (\%)

${ }^{\mathrm{b}}$ T-test.

${ }^{\mathrm{c}}$ Mann-Whitney U Test.

${ }^{\mathrm{d}}$ Likelihood ratio.

group, and were predominantly obese females. It could be suggested that LVH is related to obesity as the odds of developing $\mathrm{LVH}$ was reported to be 4.62 times higher in overweight patients compared with those of normal weight and this effect was doubled for obese compared to overweight subjects $(34,35)$. De Simone et al. demonstrated that left ventricular mass increased independent of BP in obese normotensive females (36).

Carotid intima media thickness is a well-established index of systemic atherosclerosis that correlates with the incidence and prevalence of coronary heart disease in the CKD population (37, 38). Brzosko et al. found that dialysis patients with thickened CIMT had a significantly higher incidence of IHD (39). These findings were similar to the current study, except that in the present study the cohort of patients with CKD were not on dialysis. However, atherosclerosis started as early as CKD stage II (40). The patients with thickened CIMT in the current study also had LVH, which has been well described in both the general population and dialysis population. The SHT group also had a significantly thicker median CIMT compared to the WCHT group, consistent with previous literatures (41-43). The patients with thickened CIMT were also dyslipidaemic (92\%) and two-thirds of them were diabetic There was a signifi- 
Table 5. Blood Pressure and Pulse Pressure in Both Thickened and Non-Thickened Carotid Intima Media Thickness Groups

\begin{tabular}{|c|c|c|c|}
\hline $\begin{array}{l}\text { Blood Pressure, } \\
\text { mmHg }\end{array}$ & Thick $(n=26)$ & $\operatorname{Non}$ Thick $(n=73)$ & P Value \\
\hline \multicolumn{4}{|l|}{ Clinic } \\
\hline Systolic & $168.27 \pm 16.12$ & $159.22 \pm 16.64$ & $0.18 \mathrm{e}$ \\
\hline Diastolic & $82.81 \pm 9.58$ & $80.15 \pm 8.86$ & $0.202 \mathrm{e}$ \\
\hline Pulse pressure & $85.46 \pm 18.42$ & $79.10 \pm 17.00$ & $0.110 \mathrm{e}$ \\
\hline \multicolumn{4}{|l|}{ ABPM } \\
\hline Systolic & $153.88 \pm 22.35$ & $137.88 \pm 20.62$ & $0.001 \mathrm{e}$ \\
\hline Diastolic & $82.58 \pm 11.86$ & $74.82 \pm 13.47$ & $0.011 \mathrm{e}$ \\
\hline Pulse pressure & $71.31 \pm 18.81$ & $63.05 \pm 17.71$ & $0.048 \mathrm{e}$ \\
\hline \multicolumn{4}{|l|}{ Daytime } \\
\hline Systolic & $157.23 \pm 21.46$ & $140.49 \pm 20.54$ & $0.001 \mathrm{e}$ \\
\hline Diastolic & $84.27 \pm 12.27$ & $77.19 \pm 13.84$ & $0.023 \mathrm{e}$ \\
\hline Pulse pressure & $72.96 \pm 17.91$ & $63.30 \pm 17.17$ & $0.017 \mathrm{e}$ \\
\hline \multicolumn{4}{|l|}{ Night time } \\
\hline Systolic & $146.35 \pm 25.63$ & $130.32 \pm 25.64$ & $0.007 \mathrm{e}$ \\
\hline Diastolic & $78.69 \pm 12.96$ & $71.75 \pm 131.81$ & $0.023 \mathrm{e}$ \\
\hline Pulse pressure & $67.65 \pm 19.27$ & $58.47 \pm 20.39$ & $0.048 \mathrm{e}$ \\
\hline
\end{tabular}

cant correlation between thickening of the CIMT and ageing, consistent with previous reports (40). Both univariate and multivariate analysis demonstrated that age and preexisting IHD were 2 independent predictors of thickened CIMT. The age association and atherosclerosis occurred probably due to prolonged exposure to risk factors, such as hypertension, oxidative stress, dyslipidaemia and hyperglycemia, amongst others. Age-related physiological changes, such as increased adiposity and change in sex hormones, affect lipids profile and could also play a role in atherosclerosis formation.

\subsection{Conclusions}

In conclusion, ABPM should be considered routinely in patients with HPT. Furthermore, WCHT should not be perceived as "benign" however, attention should be addressed to patients with SHT as they have worst CV outcome.

The main limitation of the current study was that $\mathrm{LVH}$ assessment was done by ECG rather than echocardiography. Recruiting patients with underlying IHD and CVA may confound the findings in the thickened CIMT group, where the association might be due to complications rather than prediction of subclinical atherosclerosis among patients with CKD.

\section{Acknowledgments}

The authors would like to acknowledge the dean of Universiti Kebangsaan Malaysia for allowing us to publish these data.

\section{References}

1. Sarafidis PA, Li S, Chen SC, Collins AJ, Brown WW, Klag MJ, et al. Hypertension awareness, treatment, and control in chronic kidney disease. Am J Med. 2008;121(4):332-40. doi: 10.1016/j.amjmed.2007.11.025. [PubMed: 18374693].

2. Salman M, Khan AH, Adnan AS, Sulaiman SA, Hussain K, Shehzadi N, et al. Attributable causes of chronic kidney disease in adults: a fiveyear retrospective study in a tertiary-care hospital in the northeast of the Malaysian Peninsula. Sao Paulo Med J. 2015;133(6):502-9. doi 10.1590/1516-3180.2015.005. [PubMed: 26760124].

3. Ravera M, Re M, Deferrari L, Vettoretti S, Deferrari G. Importance of blood pressure control in chronic kidney disease. J Am Soc Nephrol. 2006;17(4 Suppl 2):S98-103. doi: 10.1681/ASN.2005121319. [PubMed: 16565257].

4. Tedla FM, Brar A, Browne R, Brown C. Hypertension in chronic kidney disease: navigating the evidence. Int J Hypertens. 2011;2011:132405. doi: 10.4061/2011/132405. [PubMed: 21747971].

5. Hanratty R, Chonchol M, Miriam Dickinson L, Beaty BL, Estacio RO, Mackenzie TD, et al. Incident chronic kidney disease and the rate of kidney function decline in individuals with hypertension. Nephrol Dial Transplant. 2010;25(3):801-7. doi: 10.1093/ndt/gfp534. [PubMed: 19889870].

6. Agarwal R, Andersen MJ. Prognostic importance of clinic and home blood pressure recordings in patients with chronic kidney disease. Kidney Int. 2006;69(2):406-11. doi: 10.1038/sj.ki.5000081. [PubMed: 16408134].

7. Clinical Practice Guidelines for the management of Blood pressure in chronic kidney disease. 2. Kidney International; 2012.KDIGO. p. 357-62.

8. Mojon A, Ayala DE, Pineiro L, Otero A, Crespo JJ, Moya A, et al Comparison of ambulatory blood pressure parameters of hypertensive patients with and without chronic kidney disease. Chronobiol Int. 2013;30(1-2):145-58. doi: 10.3109/07420528.2012.703083. [PubMed: 23181690].

9. Ohkubo T, Kikuya M, Metoki H, Asayama K, Obara T, Hashimoto J, et al. Prognosis of "masked" hypertension and "white-coat" hypertension detected by 24-h ambulatory blood pressure monitoring 10-year follow-up from the Ohasama study. J Am Coll Cardiol. 2005;46(3):50815. doi: 10.1016/j.jacc.2005.03.070. [PubMed:16053966].

10. Dharmashankar K, Widlansky ME. Vascular endothelial function and hypertension: insights and directions. Curr Hypertens Rep. 2010;12(6):448-55. doi: 10.1007/s11906-010-0150-2. [PubMed: 20857237].

11. O’Brien E, Parati G, Stergiou G. Ambulatory blood pressure measurement: what is the international consensus?. Hypertension. 2013;62(6):988-94. doi: 10.1161/HYPERTENSIONAHA.113.02148. [PubMed: 24060895].

12. Fagard RH, Cornelissen VA. Incidence of cardiovascular events in white-coat, masked and sustained hypertension versus true normotension: a meta-analysis. J Hypertens. 2007;25(11):2193-8. doi: 10.1097/HJH.ob013e3282ef6185. [PubMed: 17921809].

13. Gorostidi M, Vinyoles E, Banegas JR, de la Sierra A. Prevalence of whitecoat and masked hypertension in national and international registries. Hypertens Res. 2015;38(1):1-7. doi: 10.1038/hr.2014.149. [PubMed: 25319601].

14. Andersen MJ, Khawandi W, Agarwal R. Home blood pressure monitoring in CKD. Am J Kidney Dis. 2005;45(6):994-1001. [PubMed: 15957127]. 
15. Minutolo R, Borrelli S, Scigliano R, Bellizzi V, Chiodini P, Cianciaruso $\mathrm{B}$, et al. Prevalence and clinical correlates of white coat hypertension in chronic kidney disease. Nephrol Dial Transplant. 2007;22(8):2217-23. doi:10.1093/ndt/gfm164. [PubMed: 17420167].

16. Shafi S, Sarac E, Tran H. Ambulatory blood pressure monitoring in patients with chronic kidney disease and resistant hypertension. J Clin Hypertens (Greenwich). 2012;14(9):611-7. doi: 10.1111/j.17517176.2012.00675.x. [PubMed: 22947359].

17. Mancia G, Fagard R, Narkiewicz K, Redon J, Zanchetti A, Bohm M, et al. 2013 ESH/ESC guidelines for the management of arterial hypertension: the Task Force for the Management of Arterial Hypertension of the European Society of Hypertension (ESH) and of the European Society of Cardiology (ESC). Eur Heart J. 2013;34(28):2159-219. doi: 10.1093/eurheartj/eht151. [PubMed: 23771844].

18. Agarwal R, Andersen MJ. Blood pressure recordings within and outside the clinic and cardiovascular events in chronic kidney disease. Am J Nephrol. 2006;26(5):503-10. doi: 10.1159/000097366. [PubMed: 17124383].

19. Bangash F, Agarwal R. Masked hypertension and white-coat hypertension in chronic kidney disease: a meta-analysis. Clin J Am Soc Nephrol. 2009;4(3):656-64. doi: 10.2215/CJN.05391008. [PubMed:19261815].

20. Jensky NE, Criqui MH, Wright MC, Wassel CL, Brody SA, Allison MA. Blood pressure and vascular calcification. Hypertension. 2010;55(4):990-7. doi: 10.1161/HYPERTENSIONAHA.109.147520. [PubMed: 20176996].

21. Di Lullo L, Gorini A, Russo D, Santoboni A, Ronco C. Left Ventricular Hypertrophy in Chronic Kidney Disease Patients: From Pathophysiology to Treatment. Cardiorenal Med. 2015;5(4):254-66. doi: 10.1159/000435838. [PubMed: 26648942].

22. Cuspidi C, Sala C, Tadic M, Rescaldani M, Grassi G, Mancia G. Is white-coat hypertension a risk factor for carotid atherosclerosis? A review and meta-analysis. Blood Press Monit. 2015;20(2):57-63. doi: 10.1097/MBP.0000000000000094. [PubMed: 25405819].

23. Guideline for Management of Hypertension. 2013.Malaysian Clinical Practice. p. 3-6.

24. Monegat M, Sermet C, Rococo E. Polypharmacy: Definitions, Measurement and Stakes Involved. Questions d'economie de la sante. 2014:5-6.

25. Grossman A, Prokupetz A, Koren-Morag N, Grossman E, Shamiss A. Comparison of usefulness of Sokolow and Cornell criteria for left ventricular hypertrophy in subjects aged $<20$ years versus $>30$ years. Am J Cardiol. 2012;110(3):440-4. doi: 10.1016/j.amjcard.2012.03.047. [PubMed: 22534054].

26. Agarwal R, Light RP. Determinants and prognostic significance of electrocardiographic left ventricular hypertrophy criteria in chronic kidney disease. Clin J Am Soc Nephrol. 2011;6(3):528-36. doi: 10.2215/CJN.07770910. [PubMed: 21088286].

27. Stein JH, Korcarz CE, Hurst RT, Lonn E, Kendall CB, Mohler ER, et al. Use of carotid ultrasound to identify subclinical vascular disease and evaluate cardiovascular disease risk: a consensus statement from the American Society of Echocardiography Carotid IntimaMedia Thickness Task Force. Endorsed by the Society for Vascular Medicine. J Am Soc Echocardiogr. 2008;21(2):93-111. quiz 189-90. doi: 10.1016/j.echo.2007.11.011. [PubMed: 18261694].

28. Muntner P, Judd SE, Krousel-Wood M, McClellan WM, Safford MM. Low medication adherence and hypertension control among adults with CKD: data from the REGARDS (Reasons for Geographic and Racial Differences in Stroke) Study. Am J Kidney Dis. 2010;56(3):447-57. doi: 10.1053/j.ajkd.2010.02.348. [PubMed: 20471734].

29. Kovesdy CP, Trivedi BK, Kalantar-Zadeh K, Anderson JE. Association of low blood pressure with increased mortality in patients with moderate to severe chronic kidney disease. Nephrol Dial Transplant. 2006;21(5):1257-62. doi: 10.1093/ndt/gfk057. [PubMed:16421161].

30. Lim YN, Ong LM, Goh BL. 21st report of the malaysian dialysis transplant registry. 2013.

31. Ridao N, Luno J, Garcia de Vinuesa S, Gomez F, Tejedor A, Valderrabano F. Prevalence of hypertension in renal disease. Nephrol Dial Transplant. 2001;16 Suppl 1:70-3. [PubMed: 11369826].

32. Sinha AD, Agarwal $R$. The complex relationship between $C K D$ and ambulatory blood pressure patterns. Adv Chronic Kidney Dis. 2015;22(2):102-7. doi: 10.1053/j.ackd.2015.01.003. [PubMed: 25704346].

33. Middleton RJ, Parfrey PS, Foley RN. Left ventricular hypertrophy in the renal patient.JAm Soc Nephrol.2001;12(5):1079-84. [PubMed:11316868].

34. Cuspidi C, Rescaldani M, Sala C, Grassi G. Left-ventricular hypertrophy and obesity: a systematic review and meta-analysis of echocardiographic studies. J Hypertens. 2014;32(1):16-25. doi: 10.1097/HJH.ob013e328364fb58. [PubMed: 24309485].

35. Wong CY, O'Moore-Sullivan T, Leano R, Byrne N, Beller E, Marwick TH. Alterations of left ventricular myocardial characteristics associated with obesity. Circulation. 2004;110(19):3081-7. doi: 10.1161/01.CIR.0000147184.13872.0F. [PubMed: 15520317].

36. de Simone G, Schillaci G, Chinali M, Angeli F, Reboldi GP, Verdecchia P. Estimate of white-coat effect and arterial stiffness. J Hypertens. 2007;25(4):827-31. doi: 10.1097/HJH.ob013e32801d1f62. [PubMed: 17351375].

37. Szeto CC, Chow KM, Woo KS, Chook P, Ching-Ha Kwan B, Leung CB, et al. Carotid intima media thickness predicts cardiovascular diseases in Chinese predialysis patients with chronic kidney disease. J Am Soc Nephrol. 2007;18(6):1966-72. doi: 10.1681/ASN.2006101184. [PubMed: 17494886].

38. Zhang L, Zhao F, Yang Y, Qi L, Zhang B, Wang F, et al. Association between carotid artery intima-media thickness and early-stage CKD in a Chinese population. Am J Kidney Dis. 2007;49(6):786-92. doi: 10.1053/j.ajkd.2007.03.011. [PubMed: 17533021].

39. Brzosko S, Lebkowska U, Malyszko J, Hryszko T, Krauze-Brzosko K, Mysliwiec M. Intima media thickness of common carotid arteries is associated with traditional risk factors and presence of ischaemic heart disease in hemodialysis patients. Physiol Res. 2005;54(5):497504. [PubMed: 15641938].

40. Preston E, Ellis MR, Kulinskaya E, Davies AH, Brown EA. Association between carotid artery intima-media thickness and cardiovascular risk factors in CKD. Am J Kidney Dis. 2005;46(5):856-62. doi: 10.1053/j.ajkd.2005.07.048. [PubMed: 16253725].

41. Tang H, Gong WY, Zhang QZ, Zhang J, Ye ZC, Peng H, et al. Prevalence, determinants, and clinical significance of masked hypertension and white-coat hypertension in patients with chronic kidney disease. Nephrology (Carlton). 2016;21(10):841-50. doi:10.1111/nep.12672. [PubMed: 26566951].

42. Cavallini MC, Roman MJ, Pickering TG, Schwartz JE, Pini R, Devereux RB. Is white coat hypertension associated with arterial disease or left ventricular hypertrophy?. Hypertension. 1995;26(3):413-9. [PubMed: 7649575].

43. Khattar RS, Senior R, Lahiri A. Cardiovascular outcome in white-coat versus sustained mild hypertension: a 10-year follow-up study. Circulation.1998;98(18):1892-7. [PubMed: 9799210]. 